\title{
Where Have All the Old Folks Gone? Interprovincial Migration of the Elderly in Canada: 1981 - 1986
}

\author{
Michael J. Bergob \\ Department of Sociology \\ University of Victoria \\ Victoria, British Columbia, Canada
}

\begin{abstract}
Changes in provincial age structures due to elderly and non-elderly interprovincial migration in Canada were examined for the 1981-86 migration interval. Although elderly and non-elderly migration patterns diverged, non-elderly migration continued to be a better predictor of changes in provincial population age structures than did elderly migration. The rate of change in provincial elderly populations was found to be significantly correlated with net non-elderly migration rates.
\end{abstract}

\section{Résumé}

La présente étude examine les changements survenus dans la structure par ầge des provinces durant la période de 1981 à 1986, lesquels changements sont attribuables aux migrations interprovinciales des personnes âgées et non âgées. Bien que les comportements migratoires des personnes âgées et non âgées soient différents, la migration de la population non âgée reste un meilleur indicateur prévisionnel de la structure par âge des populations des provinces que la migration des personnes âgées. On relève une corrélation significative entre le taux de changement de la population âgée des provinces et le taux de migration nette de la population non âgée.

Key Words: Canada, elderly, interprovincial migration

Although Zelinsky (1966:447) predicted a greater concern for the geography of the aged, many demographers have devalued migration of the elderly as an exotic topic (Flynn et al., 1985:292). This is due, in part, to the relatively small proportion of older persons who actually migrate (Rudzitis, 1984). While the elderly are significantly less likely to migrate than the non-elderly (Bryant and El-Attar, 1984), they are becoming increasingly mobile (Lee, 1980; Lichter et al., 1981; Northcott, 1985:185). Northcott (1984) indicates that elderly migration patterns can affect the population age structure at the provincial level. Therefore, the impact of an increasingly mobile elderly population, coupled with particular migration destinations, may concentrate the elderly in specific areas of Canada (Northcott, 1984).

Canada's elderly represented $10.7 \%$ of the national population in 1986 (Statistics Canada, 1987). Yet despite relatively stable elderly interprovincial migration rates (Bergob, 1990), dramatic differences have occurred in population aging at the provincial level. The differential rate of aging among the provinces can be accounted for by examining patterns of elderly and non-elderly interprovincial migration. This study examines 
the changes in provincial age structure due to elderly and non-elderly interprovincial migration in Canada during the 1981-86 migration interval.

\section{The Data}

This study is based upon data collected by Statistics Canada on the mobility status and interprovincial migration of Canadians aged five years and over for the 1981-86 census period. The data are a $20 \%$ weighted sample limited by the inclusion of multiple or return moves, emigration, mortality and the small percentage who fail to answer the questionnaire (George, 1970). As well, since elderly migrants constitute a small proportion of a small population, there may be an increased possibility of sampling error (ibid. 1970).

Interprovincial migration is defined as movements involving a change of residence from one province to another (Statistics Canada, 1989). To ensure consistency with previous migration studies, the Statistics Canada description of out-migrants with reference to their province of origin, and in-migrants with reference to their province of destination, is maintained. Canadian residents stationed outside Canada in the armed forces or the diplomatic service as well as inmates are excluded from the population universe from which mobility data are collected (Statistics Canada, 1989).

\section{The Analysis}

Analysis of the data is based upon the following: The Elderly Population Proportion is the division of the total elderly population by the total nonelderly population for Canada and each province. The Change in Elderly Population Proportion (CEPP) is the difference between the population proportion aged $65+$ in time one and the population proportion aged $65+$ in time two ( $\mathrm{t} 2 \% 65+-\mathrm{t} 1 \% 65+)$. The Rate of Change in Elderly Population Proportion (REPP) is the division of the change in elderly population proportion (CEPP) by the elderly population proportion in time one, multiplied by $100\{(\mathrm{t} 2 \% 65+-\mathrm{t} 1 \% 65+) / \mathrm{t} 1 \% 65+\} * 100$. Net Migration is the difference between in-migration (from province $i$ to province $j$ ) and out-migration (from province $j$ to province i). The Net Elderly Migration Rate (NEMR) is the division of the net migration of the population age 65 and over in time two by the population age 60 and over in time one, multiplied by $1000\left\{(t 265+/ \mathrm{t} 160+)^{*} 1000\right\}$. The population represented by $60+$ is the population at risk for migration (Northcott, 1984:5). The Net Non-elderly Migration Rate (NNMR) is the division of the net migration of the population age 5 to 64 in time two by the population age 0 to 59 in time one, multiplied by $1000\{(\mathrm{t} 25-64 / \mathrm{t} 10-$ $59) * 1000\}$. Both net migration rates can be read as a net gain or loss per 1000 original residents (Northcott, 1984:5). The Index of Dissimilarity is 
the sum of one half the absolute value of the percentage of elderly outmigration minus the percentage of non-elderly out-migration by province for the 1981-86 migration interval (ID $\left.=\Sigma^{1 / 2}|\mathrm{E} 1-\mathrm{N} 1|\right)$.

\section{Rate of Change in Provincial Elderly Populations}

In 1981, the elderly represented $9.7 \%$ of Canada's total population. By 1986 , Canada's elderly had grown to $10.7 \%$ of the total population, a rate of change of $10.3 \%$. At the provincial level, the rate of change in elderly populations ranged from a low of $4.1 \%$ for Prince Edward Island, to a high of $14.3 \%$ for Newfoundland. This rate of change in the elderly population can be partially accounted for by the demographic trend toward an increase in the number of persons aged 65 and over in the population. However, the aging of the Canadian population has been the result of declining fertility and mortality. Thus, the rapid aging of Canadian society is due more to a paucity of non-elderly than an abundance of elderly persons.

TABLE 1: CONCENTRATION OF THE ELDERLY AND NET MIGRATION RATES FOR ELDERLY AND NONELDERLY AGE GROUPS FOR 1981 - 86, BY PROVINCE.

\begin{tabular}{|c|c|c|c|c|c|c|}
\hline \multirow[b]{2}{*}{ Province } & \multicolumn{2}{|c|}{$\begin{array}{l}\text { Percentage* of } \\
\text { Population } 65+\end{array}$} & \multirow{2}{*}{$\begin{array}{l}\text { Change in } \\
\text { Percent Elderly } \\
1981-86\end{array}$} & \multirow{2}{*}{$\begin{array}{l}\text { Rate of } \\
\text { Change** }\end{array}$} & \multicolumn{2}{|c|}{ Net Migration Rate } \\
\hline & 1986 & 1981 & & & Nonelderly & Elderiy \\
\hline $\begin{array}{l}\text { Newfoundland } \\
\text { Prince Edward Island } \\
\text { Nova Scotia } \\
\text { New Brunswick } \\
\text { Quebec } \\
\text { Ontario } \\
\text { Manitoba } \\
\text { Saskatchewan } \\
\text { Alberta } \\
\text { British Columbia }\end{array}$ & $\begin{array}{r}8.8 \\
12.7 \\
11.9 \\
11.1 \\
10.0 \\
10.9 \\
12.6 \\
12.7 \\
8.1 \\
12.1\end{array}$ & $\begin{array}{r}7.7 \\
12.2 \\
10.9 \\
10.0 \\
8.9 \\
10.1 \\
11.9 \\
12.0 \\
7.3 \\
10.9\end{array}$ & $\begin{array}{l}1.1 \\
0.5 \\
1.0 \\
1.0 \\
1.1 \\
0.8 \\
0.7 \\
0.7 \\
0.8 \\
1.2\end{array}$ & $\begin{array}{r}14.3 \\
4.1 \\
9.2 \\
9.9 \\
12.4 \\
7.9 \\
5.9 \\
5.8 \\
11.0 \\
11.0\end{array}$ & $\begin{array}{r}-31.7 \\
14.1 \\
8.1 \\
-2.8 \\
-10.1 \\
12.9 \\
-0.6 \\
-2.7 \\
-13.8 \\
2.3\end{array}$ & $\begin{array}{r}-1.5 \\
4.2 \\
3.5 \\
4.1 \\
-8.0 \\
2.8 \\
-5.9 \\
-3.9 \\
-0.3 \\
9.4\end{array}$ \\
\hline Canada & 10.7 & 9.7 & 1.0 & 10.3 & & \\
\hline
\end{tabular}

* Adapted from Statistic Canada, Cat. No. 93-101, 1987.

** Adapted from Statistics Canada, Cat. No. 93-108, 1989.

Population aging is also affected by migration. While immigration remains newsworthy, its contribution to Canadian population growth is minimized by concomitant emigration from Canada. However, interprovincial migration patterns are an important factor in determining population age structures. For example, during the 1981-86 migration interval, Newfoundland lost 31.7 non-elderly persons per 1000 original population (age 0-59), compared to a loss of only 1.5 elderly persons per 1000 original population (age 60 and over). In this instance, the migration of nonelderly persons from Newfoundland contributed to the aging of this provincial population. 
In contrast, Quebec experienced a relatively similar net loss of elderly (8.0) and non-elderly (10.0) persons per 1000 original population. This would indicate that Quebec's aging population is not as strongly influenced by interprovincial migration as by a decline in fertility and mortality. While Quebec has been affected by an Anglophone out-migration, the age distribution of these out-migrants requires further investigation. However, the population age structure of Quebec during the 1981-86 migration interval was clearly marked by a loss of both elderly and non-elderly interprovincial migrants. The smallest rate of change in elderly population proportion was experienced by Prince Edward Island. A 14.1 net nonelderly migration rate offset a 4.2 net elderly migration rate, to slow the aging of Prince Edward Island's population. Thus, while Prince Edward Island had the second highest net migration of elderly persons, it also had the highest net migration of non-elderly. This resulted in a relatively low $4.1 \%$ rate of change in provincial age structure. It is the relative impact of interprovincial migration on the provincial populations that is now examined.

\section{Correlation Between Non-elderly and Elderly Migration and Provincial Population Aging}

In order to ascertain the singular and combined effects of non-elderly and elderly net migration, a regression analysis was calculated with Change in the Percent Elderly (from 1981 to 1986) as the dependent variable, and Net Non-elderly and Net Elderly Migration Rates as the independent variables. The regression equation for the Predicted Change in the Percent Elderly was: $P=-0.64 \mathrm{~N}+0.45 \mathrm{E}$ with an adjusted $\mathbf{R}^{2}=0.18$. The $R^{2}$ was adjusted to account for the small number of cases (Northcott, 1984:17). These results were statistically significant (one-tail test, $p<0.05$ ), and indicate a change in net migration trends from previous studies (Bergob, 1990).

Comparison with Northcott (1984) indicates a notable change in the correlation between the variables in the regression equation. In particular, none of the partial correlations for predicted change in population were statistically significant $(p>0.05)$. The correlation between the independent variables $(0.44 \mathrm{p}>0.05)$ indicated that non-elderly and elderly net migration may have had independent effects upon the provincial population age structures in this data set.

This was most apparent in British Columbia, where a relatively low net non-elderly migration rate (2.3) was contrasted by a relatively high net elderly migration rate (9.4). In this instance, the influx of elderly persons to British Columbia contributed to a $1.2 \%$ change in the percentage of 
elderly. This is a dramatic reversal of the trend indicated by Northcott (1984), in which British Columbia had net non-elderly migration rates of 24.4 (1956-61) and 47.0 (1971-76) compared with net elderly migration rates of 17.7. (1956-61) and 21.2 (1971-76). The rate of change in British Columbia's population age structure increased from the third lowest (4.3) in 1971-76 (Northcott, 1984) to the third highest (11.0) in 1981-86. Thus the impact of elderly in-migration became apparent with the decline in British Columbia's net non-elderly interprovincial migration rate.

TABLE 2: CORRELATION COEFFICIENTS BETWEEN ELDERLY AND NONELDERLY MIGRATION RATES AND MEASURES OF POPULATION AGING, 1981-86.

\begin{tabular}{|c|c|c|c|}
\hline & $\begin{array}{l}\text { Net Nonelderly } \\
\text { Migration Rate } \\
\text { (r) }\end{array}$ & $\begin{array}{l}\text { Net Elderly } \\
\text { Migration Rate } \\
\text { (r) }\end{array}$ & $\begin{array}{l}\text { Net Elderly Migration Rate } \\
\text { Controlling for Nonelderly } \\
\text { Migration } \\
\quad \text { (partial r) }\end{array}$ \\
\hline $\begin{array}{l}\text { Change in percentage } \\
\text { Elderly } 1981-86\end{array}$ & $(p=.098)$ & $\begin{array}{l}0.16 \\
(p=.326)\end{array}$ & $\begin{array}{l}0.45 \\
(p=.227)\end{array}$ \\
\hline$P=-.64 N+.45 E R 2=.18$ & & & \\
\hline $\begin{array}{l}\text { Rate of Change in } \\
\text { Percentage Elderly } \\
1981 \text { - } 1986\end{array}$ & $\begin{array}{l}-.74 \\
(p=.007)\end{array}$ & $\begin{array}{l}-0.04 \\
(p=.457)\end{array}$ & $\begin{array}{r}0.48 \\
(p=.189)\end{array}$ \\
\hline $\mathrm{R}=-.90 \mathrm{~N}+.36 \mathrm{E} R 2=.56$ & & & \\
\hline
\end{tabular}

Source: See Table 1.

The only significant partial correlation occurred for the Predicted Rate of Change. The regression equation for Predicted Rate of Change was: $R=$ $-0.90 \mathrm{~N}+0.36 \mathrm{E}$ with an adjusted $\mathrm{R}^{2}$ of $0.56(\mathrm{p}<0.05)$. The rate of change in the provincial population age structures was more likely to be predicted by net non-elderly migration than by net elderly migration. Net elderly migration was negatively correlated with the predicted rate of change and not statistically significant ( $p>0.05)$. Controlling for net non-elderly migration in the regression analysis indicated a non-significant partial correlation $(0.48, p>0.05)$ between net elderly migration and the predicted rate of change. Net non-elderly migration had a significant partial correlation $(-0.74, \mathrm{p}<0.05)$ with the predicted rate of change in the provincial population age structure.

These results indicate that non-elderly migration remains an important determinant of the rate of change in the population age structure of most provinces. The negligible impact of elderly migration on provincial populations remains due to their comparatively small number. However, the rapid aging of Canadian society increases the potential effect of elderly interprovincial migration on provincial population age structures. 


\section{Where Have All the Old Folks Gone?}

The Index of Dissimilarity was used to compare elderly and non-elderly migration streams calculated from the out-migration of residents from a particular province. The Index of Dissimilarity for the 1981-86 migration interval ranged from a low of 8.2 for Quebec, to a high of 31.9 for Alberta. The Index of Dissimilarity indicates that Quebec's elderly had only slightly different preferences from the non-elderly for migration destinations. The comparatively large Index of Dissimilarity for Alberta was due to the elderly's choice of British Columbia as the preferred destination, while the non-elderly chose Ontario. When migration destinations differ greatly between elderly and non-elderly out-migrants, a large Index of Dissimilarity will generally result.

TABLE 3. OUT-MIGRATION STREAMS OF ELDERLY AND NONELDERLY POPULATIONS FOR 1981, BY PROVINCE, INDICATING INDEX OF DISSIMILARITY

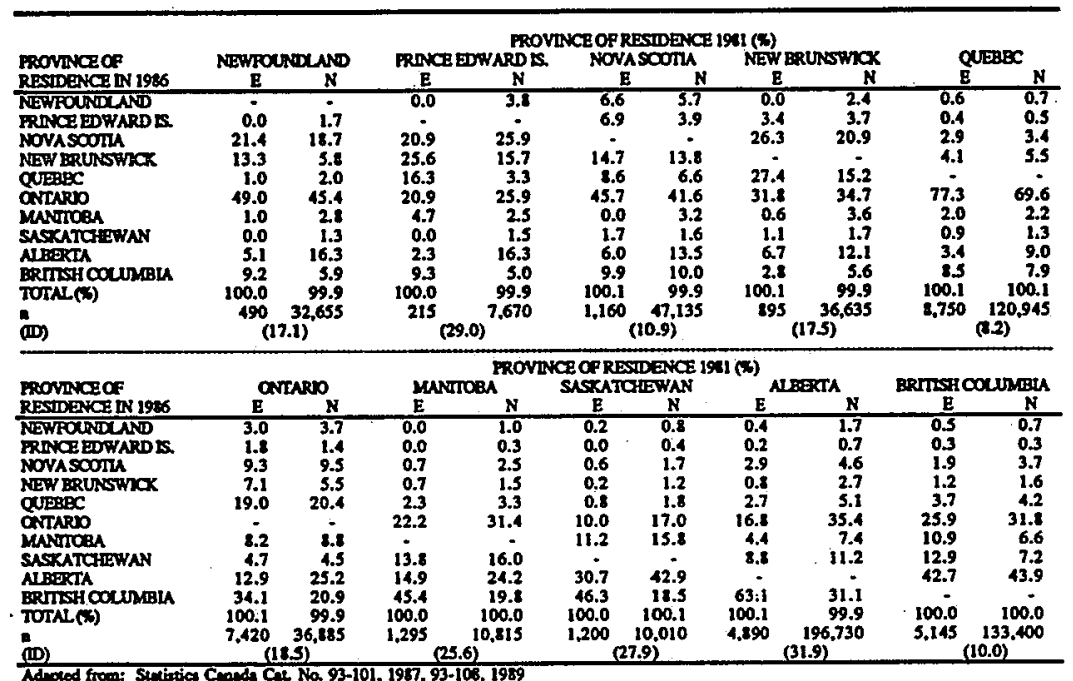

In comparison with the 1971-76 migration interval (see Northcott, 1984), the Index of Dissimilarity scores for Newfoundland, Nova Scotia, Ontario and Manitoba became less dissimilar. Manitoba had the largest relative decrease in dissimilarity between elderly and non-elderly migration destinations from the 1971-76 interval. Manitoba's elderly out-migration to Ontario declined from $53.4 \%$ to $22.2 \%$; however, the proportion of elderly Manitoba out-migrants to Saskatchewan increased from $7.0 \%$ to 
$15.7 \%$ and to British Columbia from $27.1 \%$ to $45.4 \%$. The migration destinations of Manitoba's non-elderly remained relatively consistent with 1971-76 migration destinations (see Northcott, 1984).

The Index of Dissimilarity scores for Prince Edward Island, New Brunswick, Quebec, Saskatchewan, Alberta and British Columbia became more divergent from those indicated by Northcott (1984) for the 1971-76 migration interval. Prince Edward Island indicated the largest change in migration destination preferences between elderly and non-elderly outmigrants for the 1981-86 interval. The proportion of Prince Edward Island's elderly out-migrants who moved to Nova Scotia declined from $34.0 \%$ to $20.9 \%$, and from $24.0 \%$ to $20.9 \%$ for Ontario as a migration destination. The elderly who migrated from Prince Edward Island to New Brunswick increased to $25.6 \%$ from $20.0 \%$. Quebec's share of elderly migrants from Prince Edward Island increased from $6.0 \%$ to $16.3 \%$.

Elderly out-migrants from the Prairies and Ontario chose British Columbia as a destination, while Nova Scotia, New Brunswick and Quebec elderly out-migrants went to Ontario. The Newfoundland and Prince Edward Island elderly migrated to Nova Scotia and New Brunswick, respectively. Non-elderly migrants from Quebec, Newfoundland, Nova Scotia, Alberta, New Brunswick and Manitoba indicated a continued preference for Ontario, while British Columbia, Saskatchewan and Ontario non-elderly migrants chose Alberta as a migration destination. Prince Edward Island non-elderly were equally attracted to Ontario and Nova Scotia.

The increase in the dissimilarity of migration destinations between elderly and non-elderly interprovincial migrants requires further investigation. The hypothesis that elderly and non-elderly migrants share a preference for specific migration destinations may be rejected in future research.

\section{Conclusion}

The most important aspect of the age distribution of Canada has been the continuation of population aging due to decreasing fertility and mortality (Dumas, 1987). Examination of the 1981-86 migration interval revealed an increase in the rate of change in the population age structure of most of the provinces. In some instances, this rate of change was higher than the national average. The differential rates of change in provincial population age structures can be attributed to the impact of interprovincial migration.

Net non-elderly interprovincial migration remained an influential factor in affecting provincial population age structures in the 1981-86 migration 
interval. This was most evident in Newfoundland's high rate of non-elderly out-migration during this migration interval. Quebec and Alberta also encountered a loss of non-elderly persons, though at a lower rate than Newfoundland. This loss of non-elderly persons was not British Columbia's gain. British Columbia's rate of non-elderly in-migration decreased by $95.1 \%$ from the $1971-76$ migration interval. The impact of high elderly in-migration became apparent in the change in percent elderly in British Columbia's population age structure for the 1981-86 migration interval.

The number of non-elderly and elderly migrants remained comparable to the 1971-76 migration interval (Bergob, 1990). Elderly out-migration remained consistent with 1971-76 rates for the eastern provinces, while Quebec, Alberta and British Columbia had higher rates of elderly outmigration than previously noted (see Northcott, 1984). The remaining provinces all indicated decreases in elderly out-migration. Newfoundland, Alberta and British Columbia all had increases in non-elderly outmigration from the 1971-76 migration interval, while the remaining provinces indicated similar or decreased rates.

Compared to the 1971-76 migration interval (see Northcott, 1984), elderly and non-elderly migration patterns diverged in the 1981-86 migration interval. This indicates that elderly and non-elderly interprovincial migrants were more independent in their migration patterns and destinations than previously indicated. Thus, increased dissimilarity between elderly and non-elderly interprovincial migrants, coupled with an increasingly mobile elderly population, may have a significant impact upon the provincial population age structure of specific migration destinations. While there was no overall increase in elderly interprovincial migration during the 1981-86 migration interval, the potential effect on provincial population age structures cannot be ignored in future research.

\section{Acknowledgments}

An earlier version of this paper was presented at the 19th Annual Scientific and Educational Meeting of the Canadian Association on Gerontology, 25-28 October 1990, in Victoria, British Columbia. The author would like to thank Jean E. Veevers, Paul M. Baker, Wayne W. McVey, Jr., and two anonymous reviewers for their suggestions and comments in the development and revision of this paper. The author retains sole responsibility for error. 


\section{References}

Bergob, M.J. 1990. An examination of migration trends among Canada's elderly. Unpublished paper, Department of Sociology, University of Victoria, British Columbia, Canada.

Bryant, E. and M. El-Attar. 1984. Migration and redistribution of the elderly: A challenge to community services. Gerontologist 24:634-640.

Dumas, J. 1987. Current Demographic Analysis: Report on the Demographic Situation in Canada, 1986. Ottawa, Ontario: Minister of Supply and Services.

Flynn, C.B., C.F. Longino, Jr., R.F. Wiseman and J.C. Biggar. 1985. The redistribution of America's older population: Major migration patterns for three census decades, 1960 1980. Gerontologist 25:292-296.

George, M.V. 1970. Internal Migration in Canada: Demographic Analyses. Ottawa, Ontario: Queen's Printer.

Lee, E.S. 1980. Migration of the aged. Research on Aging 2:131-136.

Lichter, D.T., G.V. Fuguitt, T.B. Heaton and W.B. Clifford. 1981. Components of change in the residential concentration of the elderly population: 1950-1975. Journal of Gerontology 3:3-22.

Northcott, H.C. 1984. The interprovincial migration of Canada's elderly: 1956-61 and 1971-76. Canadian Journal on Aging 3:3-22.

. 1985. The geographic mobility of Canada's elderly. Canadian Studies in Population 12:183-202.

Rudzitis, G. 1984. Geographical research and gerontology: An overview. Gerontologist 24:536-542.

Statistics Canada. 1987. Age, Sex and Marital Status. Catalogue no. 93-101. Ottawa, Ontario: Minister of Supply and Services.

1989. Mobility status and interprovincial migration. Catalogue no. 93-108. Ottawa, Ontario: Minister of Supply and Services.

Zelinsky, W. 1966. Toward a geography of the aged. Geographical Review 56:445-447.

Received July, 1990; revised July, 1991. 
